\title{
The Language of Life. DNA and the revolution in personalized medicine. Francis S. Collins New York etc.: Harper, 2011
}

\section{HUB ZWART ${ }^{1,2}$}

A lot has been written ... about the DNA revolution. But this book aims to be about the facts (Collins 2010, p.xxv)

Francis Collins had an impressive track record as a gene hunter (cystic fibrosis, neurofibromatosis, Huntington's disease) when he was appointed Director of the Human Genome Project (HGP) in 1993. In June 2000, together with Craig Venter and President Bill Clinton, he presented the draft version of the human genome sequence to a worldwide audience during a famous press conference. And in 2009, President Barack Obama nominated him as director of the National Institutes of Health (NIH), the largest Tfunding agency for biomedical research in the world.

In 2006, Collins published his book The Language of God, $^{3}$ an autobiographical account of the HGP and its scientific, historical, and societal significance, with special attention paid to the impact of the human sequence on the way we see our world and ourselves. ${ }^{4}$ Now, by way of a sequel, he wrote The Language of Life. Whereas The Language of God focused on the genome sequence of mankind in general, and on the HGP as a "revolution" in biomedicine, the new book, as indicated by its subtitle, is oriented towards "the revolution in personalized medicine", the impact of the genomics revolution on the personal lives of individuals.

Before subjecting Collins' book to a closer reading, I first of all would like to explain how I will read it and from what perspective. Why is genomics in general, and the HGP and its aftermath in particular, a subject of interest to a philosopher like me? Why did I become interested in assessing the HGP and in studying the work and views of some of its key contributors?

\section{Disruptive changes and the agenda of philosophy}

As my background is in continental philosophy, my research builds on the 'continental school' within the philosophy of science. In this school, the French philosopher Michel Serres has played a decisive role, not least because of the significant impact his work has had on the views and methods of authors such as Foucault, Deleuze and Latour. In his book Hermes I, published in 1968 (the year of the May revolt), he argued that we live in an era of disruptive change, in science as well as in politics and other domains. ${ }^{5}$ Within the scientific realm, he claimed, the era of disruption is exemplified by the emergence of large-scale, high-tech, transdisciplinary research fields such as molecular biology.

In Hermes I, Serres basically argued that philosophy had lost track of these developments and had become hopelessly outdated and irrelevant as a consequence. 
In subsequent volumes of his Hermes series, however, a slightly more optimistic view is taken. ${ }^{6}$ Philosophy can be rescued and reanimated, Serres now argues, by taking an "empirical turn". Philosophers can still play a pivotal role, provided that they acquaint themselves thoroughly with these newly emerging worlds of knowledge and research, from a position of close proximity. They must enter the capillaries and tissues of technoscience and really become embedded scholars. They must address the various philosophical issues raised by these developments in close interaction with the scientists involved. Thus, what Kant envisioned as an epistemology of pure reason should evolve into a kind of conceptual epidemiology, analysing and critically assessing the ways in which techniques, vocabularies, research practices and forms of information spread through research fields worldwide. Philosophers may then study, for instance, how in laboratories throughout the world, matter has given way to information as the key target of scientific inquiry.

For Serres in the 1960s and 1970s, molecular biology was the place to be, the arena where the revolution manifested itself. For later generations of philosophers who are willing to following his lead, genomics has come to play a rather similar role during the past two decades or so. Genomics has widely been regarded as a true "revolution" in science ${ }^{7}$ and its main focus event, beyond doubt, was the June 2000 press conference mentioned above, where a draft version of the human sequence was presented to a group of prominent representatives of science and politics actually present, as well as to a global audience worldwide - Urbi et orbi, as it were. The sequence was presented as an important milestone for science as well as for humanity, and the focus was on the massive implications this achievement was to have for how biomedical research is conducted and medical health care is provided. Or, as Collins phrases it in his most recent book: "The HGP [is] considered by many to be one of the boldest scientific efforts that humankind has ever mounted." (p.299) Indeed, one of the claims made during the conference was that "Our children's children will know the word cancer only as a constellation of stars."

In 2010, the journal Nature published a retrospective. The basic question was: has the proclaimed genomics revolution arrived? Collins ${ }^{8}$ and Venter ${ }^{9}$ both contributed to the issue. Their answer and that of other contributors was, essentially: not yet. The most important outcome of the HGP resides in the acknowledgment that life is much more "complicated"10 than was envisioned back in 1989, when Francis Collins wrote his very first e-mail and the HGP was about to be launched.

But this has not put an end to revolutionary science rhetoric - quite the contrary. The great expectations are still there. They are simply transferred from the general human sequence, deciphered by the HGP, to the coming of the personal genome. And that is, as I see it, a telling example of what Freud in The Interpretation of Dreams called "displacement" ("Verschiebung"). ${ }^{11}$ The enchanting dream scenarios are still very much alive, but they are transferred from the original object (the sequence of humankind as such) to the alluring substitutes (such as $\$ 1000$ personal genome sequencing) that are currently emerging in the arena of personalised medicine and personalised genomics. In my view, Collins' book is a rather symptomatic exemplification of this "displacement", of this trend. The implication is not that these 
claims concerning the revolutionary nature of personalised medicine are false, or that they should be discarded right away as political tricks employed by research managers in their frantic search for novel streams of funding to keep their research communities alive. Rather, they provide us with a window into the concerns and desires that continue to fuel our contemporary will to know. ${ }^{12}$

As I said, I regard Collins' book as a "case study" of this phenomenon. In my review I will employ a specific way of reading for which the French philosopher Althusser coined the term "reading aloud". ${ }^{13}$ The focus is on the discourse as such, and the floor first and foremost is given to the author himself. The tensions and crevices in his writings are bound to manifest themselves and become 'audible', and will be brought to the fore by reading carefully, by paying attention, not only to the content of the text, but also to the 'sound' of the language, the choice of words, the texture, the discursive ambiance as it were. Practically, it means that my reading will involve the use of quite a few quotations from the text.

\section{Reading aloud}

Chapter One of the book begins:

Scientists aren't generally prone to effusiveness. We are privately excited about our work, but in public we often, and rightly, emphasize skepticism and caution. But there are exceptional moments where skepticism is set aside, electricity fills the room, and a scientist with palpable passion and flashing eyes describes unabashedly a change in the landscape that will have lasting significance. Just a few months into the new millennium, I had that experience ... After much anticipation, and many tumultuous moments, the achievement of an almost impossible audacious goal that had motivated all of us for a decade was now essentially assured. (p.1)

This is not a reference to the June 2000 HGP press conference, but to a previous event: the "private, science-only version" (p.2) that took place in May 2000 at Cold Spring Harbor, "the Mecca where genome scientists made their pilgrimages every year" (p.2). The public announcement of the complete draft of the genome would follow one month later. This is how Collins "unabashedly" described the change in the landscape at that "science-only" ceremonial meeting:

We have been engaged in a historic adventure. Whether your metaphor is Neil Armstrong or Lewis and Clark, your metaphor is at risk of falling short. There is no question that the enterprise we have gathered here to discuss will change our concepts of human biology, our approach to health and disease, and our view of ourselves. (p.2)

And:

With the sequencing of the entire genome, scientists could launch into a dizzying array of groundbreaking research projects to unlock the greatest secrets of the human body ... We had climbed to the top 
of the mountain, and we were about to start rushing down the other side, into a valley full of potential discoveries. (p.2)

The core of the message is this: raising public expectations is not at all part of the daily business of science. It is only on very rare and exceptional occasions that the music of science is played in such a blazing key. Still, Collins is not disinclined to emphasise that he actually led what he describes as one of the boldest scientific efforts that humankind has ever mounted (p.299).

What is left out of the picture thus painted is the pecuniary aspect of things. The expedition towards the genome summit required substantial funding, and with this in mind, the metaphor is slightly misleading. In Collins' story it looks as if, after having received a significant amount of public investments - amounting to a $\$ 3$ billion dollar grant - in order to pull them towards the top, the sciences can now be left to their own resources as they are now gliding down the slope. In fact, the human sequence was only the beginning. It is something like the first terrace of an extended and forbidding mountain range. Getting to the primary peak was a moment of high visibility for science. But now that the expedition has moved on beyond this first summit, researchers feel they are no longer within eyesight of their audiences. And this clearly is an issue of concern, because more funding will be needed for future stages:

Nearly a decade has passed since that moment of celebration.

Virtually all biomedical researchers would agree that their approach to understanding how life works has been profoundly and irreversibly affected by access to the complete DNA sequence of the human genome ... But the effect on the public of all the hoopla in 2000 has been mixed. Most people know that the genome has been spelled out, but they have lost track of what has happened since then. They remember the ascent of the mountain, but they are unaware of the rewards that are starting to appear in the valley. Some of the press announcements at the time implied an immediate transformation of medicine, but that was never realistic - lead times between basic discoveries in science and changes in practical medicine, technology, or daily life tend to be measured in decades. (p.3)

In other words, the HGP has genuinely and dramatically affected science, but its implications for society seem hardly noticeable as yet. Partly due to the fact that mass media excessively amplified the 'hoopla' of the year 2000, the whole endeavour now threatens to go awry. ${ }^{14}$ That is a major threat because, on the slope at the opposite side, hardly noticeable to the public eye, the revolution is still raging. And that is what fuels the basic message of the book. The revolution is ongoing, and societies should still prepare themselves for a massive disruptive change, one that has taken more time to come about than expected perhaps, but is, nonetheless, still on its way:

Healthy individuals are increasingly able to discover some of their body's inner secrets and take appropriate action. The potential for individual prediction is beginning to spill out to the general public, offering the opportunity to take more control of your fate ... None of this is happening overnight, and ultimate success will depend upon 
the visionary investment of energy, talent, and financial resources by scientists, governments, universities, philanthropic foundations, biotechnology and pharmaceutical companies, and the general public. But without question, man's knowledge of man is undergoing the greatest revolution since Leonardo. (p.5, my italics)

This is an important quote because, more or less in passing, the financial dimension is finally being addressed. The revolution can only come about if governments and others continue to invest substantial "financial recourses" in the endeavour. In order for the genomics revolution to be really unleashed, funding is not a one-time injection, but a permanent necessity. I will now further illustrate Collins' argument with the help of a few examples taken from his book

\section{A case of lumpectomy}

After being diagnosed with breast cancer, Karen (a pseudonym) underwent lumpectomy and the removal of 23 lymph nodes, Collins tells us. Tests for BRCA1 and BRCA2 were negative. After radiation treatment, she was faced with the decision whether to proceed with chemotherapy, as recommended by three different oncologists. Then a family member informed her about a gene expression analysis to test the tumour's likely aggressiveness. On the basis of this test, she decided to skip chemotherapy and to pursue hormonal therapy alone. "This", according to Collins, "represents one of the first fruits of the genomics revolution, and Karen is one of its pioneers" (p.4). Her case:

exemplifies a new approach to medicine that will affect virtually all facets of health care ... many accepted principles of medicine and biology require substantial revision ... Healthy individuals are increasingly able to discover some of their body's inner secrets and take appropriate actions. (p.5)

No one will deny, I gather, that in this case the opportunity provided by genetic testing to forego chemotherapy was highly beneficial to the patient involved. And yet, something more must be expected when it comes to presenting evidence for the claim that we are witnessing a breathtaking revolution that changes medicine, biology and human life. During the past two centuries, medicine has been experiencing progress and innovation more or less continuously. What Collins describes is basically the availability (in certain cases) of an additional source of information that may enhance the quality of decision-making in therapy settings. But events like that, I would argue, happen all the time, as more tools for diagnosis and treatment are being developed quite regularly. It represents an improvement, surely, but not a quantum leap. Taken in isolation, the case does not prove that much. What about a slightly different case, for instance, where a gene test will encourage rather than discourage chemotherapy, or where genome information (usually expressed in terms of probabilities and risks) will make a difficult decision even more bewildering, due to statistical information overload? For a revolution to be real, one would expect completely new horizons and vistas to be opened up. But, of course, Collins' book contains examples of this as well. They notably emerge whenever genomics becomes closely interwoven with other high profile areas of inquiry, such as brain research and stem cell research. 


\section{Brain genomics}

Collins grew up on a farm inTT Shenandoah Valley, Virginia, where his father was a collector of American folk songs, and for Collins the story of brain genomics begins with folk musician Woody Guthrie who died at 55 from a highly inheritable neurodegenerative illness, Huntington's disease. But this is a classical monogenetic affliction. What added value can personalised genomics offer?

Of all the organs in the body, Collins argues, "the brain is the one where environmental interactions are most crucial" (p.187). External stimulation during childhood is essential for brain development, and throughout life the experience of learning results in changes in neuronal connections, while these same neuronal connections can be more or less irreversibly disrupted by illness or drugs (p.187). Still, brain functioning involves a tremendous amount of input from our 20,000 or so protein-coding genes.

One of the examples Collins uses to herald the new era of brain genomics is alcohol dependence. As Collins explains, we now understand that alcohol, after producing its immediate mental effect, is converted by enzymes to acetaldehyde, a toxic substance, and finally to acetate, an energy source. Some individuals, according to their genetic disposition, have a slow-acting first enzyme and a fast-working second enzyme. For them, alcohol intoxication is a pleasurable experience for quite an extended period of time, before the untoward effects of acetaldehyde become noticeable. They are likely to be more prone to alcohol abuse. In others, the effects of acetaldehyde become noticeable quite soon, because the first enzyme acts faster and the second one slower, and therefore, they tend not to like alcohol that much.

Once again, although it may be enlightening to understand the biochemistry of the process in more detail, this in itself does not constitute sufficient evidence for convincingly making the case that we are experiencing a remarkably high tide of revolutionary changes and horizon expansions. Individual differences in enjoying alcohol use are already common knowledge, I would say, and each of us will probably know from experience into which of the two categories described above he or she is most likely to fall, without the need for genetic testing. Will knowledge concerning the genes involved really affect the management of our daily lives?

Another example given by Collins is the impact of the personalised genomics revolution on assessing personality traits. Currently, personality tests such as the Myers-Briggs test are quite commonly used, notably in human resources management (assessing the personality traits of job applicants and employees). In recent years, a number of genes associated with personality traits have entered the stage. As Collins makes clear, four of these seemed to be strongly inherited: genes associated with novelty seeking, harm avoidance, reward dependence and persistence. A gene called DRD4, for instance, involved in dopamine metabolism, has been baptised the noveltyseeking gene. As Collins himself points out, however, follow-up studies have failed to confirm the initial claims. And although some genes may contribute to these 
personality traits, each of the many genes involved will contribute a very small effect, so that "claims of predictability of personality traits based on DNA testing should be taken with considerable skepticism" (p.200). The same holds for the genetic basis of another personality trait, "infidelity". Given that bonding behaviour differs so widely among various species of mammals and birds (ranging from faithful species of swans who display monogamous bonding to chimpanzees, who are notoriously promiscuous), a genetic component may be involved. But again, although companies offer genetic fidelity tests on the web, Collins himself advocates scepticism in this matter:

"Do not be misled ... the actual influence on the behaviour on an individual male [of the gene in question] is quite modest, and should certainly not be used in mate selection or as an excuse for cheating one's partner" (204).

For indeed:

"a full understanding of the way the brain functions ... is still a distant goal for science ... Our human brains may simply not be sufficiently complex to understand themselves" (p.207).

In short, given the multitude of relatively weak genetic factors, DNA analysis will be of limited utility when it comes to assessing personality traits (p.208). At the same time Collins continues to opine that brain genomics will have revolutionary effects, albeit predominantly in the treatment of psychiatric disorders: "genetic factors predisposing to the major mental disorders will emerge in the next few years" (p.207). For such disorders we can "anticipate significant advances ... in the near future" (p.207).

In other words, we are faced with a sequence of claims that seem difficult to combine. Claim 1 asserts that we are in the middle of a revolution that will change science, medicine and human life. Claim 2 asserts that, up to now, concrete instances of progress are actually quite modest, due to the astounding complexity of genomes, brains, and other items on the list of biological research. Claim 3 insists nonetheless that important breakthroughs (albeit difficult to specify as yet) will most certainly come about in the near future.

\section{Genomics and the iPS Cell revolution}

The same pattern emerges where Collins addresses the genomics research agenda in the context of current developments in stem cell research aimed at developing therapies for degenerative diseases. In Collins' view, given the persistent constraints on and drawbacks of gene therapy as well as whole organ transplantation, stem cell therapy has the potential to provide the optimal solution. For indeed, "If delivery of genes to cells is potentially beneficial but technically challenging, why not just deliver the cells?" (p.260). As Collins argues, our ability "to reprogram human cells has opened up an entirely new vista of potential therapeutics" (261). This builds up to the conclusion once again that a revolution is in the making. 
"Only a few times in my career have I witnessed a scientific development that qualifies as a true revolution" (p.266)

But our ability to transform a cell into a stem cell in the laboratory (i.e. the production induced pluripotent stem cells - iPS cells) was such a moment:

"It opens up a new window for research and potential clinical applications" (266).

Utterances of this type reside under the heading of what I referred to as Claim 1. They proclaim and outline a revolution in the making. Yet, again, this set of utterances is immediately followed by Claim 2- and then Claim 3-type utterances:

"The therapeutic use of iPS cells is still very uncertain... (p.266) [Claim 2]

In fact:
"before we get too carried away about the potential of iPS cells to cure a long list of degenerative diseases, it should be mentioned that there are serious existing concerns about whether such cells might be, shall we say, a bit too exuberant in their potential, actually causing tumours in the person receiving them ... I will be several years before the potential of iPS cells for therapeutics can be determined, but it is entirely possible that this approach will find clinical application" (267) [Claim 2].

Nonetheless, it is argued that the development of iPS cells "holds great promise" (p.167) [Claim 3]. To this, Collins adds what he refers to as the first law of technology: "The consequences of a radical new technology are almost always overestimated in the short term and underestimated in the long term" (p.268).

So, again, we are confronted with a script consisting of three components. First, we are told that we are witnessing a revolution (a "disruptive innovation", p.275). Second, it is made clear that concrete results so far are contentious and far from revolutionary in themselves. Yet third, it is maintained that it is undeniable that we are about to enter a completely new landscape.

\section{Will the revolution arrive?}

The vital question, then, is what is needed in order to turn these highly uncertain prospects into a really revolutionary change, into a "disruptive innovation"? The answer is given quite explicitly:
"We live in an exciting time in medical research, where a series of 'disruptive innovations' promise to revolutionize diagnosis, prevention and treatment. But this revolution will sputter out if we do not make continued major investments in the research needed to explore these new approaches. Worldwide, medical research is seriously underfunded in nearly all countries..." (p.275, my italics). 
In other words, in order to make it all happen, in order to cross the valleys of uncertainty between 'terrace one' and the subsequent peaks, this type of research will be in need of sustained massive funding, as scientists continue their ascent towards an ever-retreating summit, a final peak still shrouded in mist, in a mountain range of ever-increasing complexity.

And this reveals a (potentially fatal) flaw or weakness in the narrative. The human sequence - the first terrace in the mountain landscape - provided a clear focus, a challenging target, something with which politicians and others could identify. Beyond this peak, this vision is bound to become blurred, with multiple targets arising and the distances between the research teams climbing through this landscape and their audiences at the foot of the mountains continually increasing. All these factors, in combination with financial crises, global competition, and other form of societal turbulence, will make it increasingly difficult to convince governments to continue to invest in complex research that may become disruptive in the future. In other words, with this book, Francis Collins once again assumes the role of spokesperson for a major campaign to reach "an almost impossible audacious goal": ascertaining novel funding streams for "big biology" whose results so far, from a societal perspective at least, are fairly disappointing. The claim that the $\$ 1,000$ genome will "enable a personalized plan of preventive medicine to be established" is not supported by the evidence as presented.

Collins' book is fairly disappointing in other respects as well. I take it as rather symptomatic for the approach adopted by the author that, instead of using the June 2000 press conference as his point of departure, as is done in previous publications, Collins now prefers the "science-only" celebration that took place one month earlier. This is symptomatic of the fact that the book conveys a "science-only", technologydriven vision of future developments. The various pitfalls and concerns involved in personalised medicine and human genome sequencing are more or less delisted from the agenda, in order to clear the way, as it were, for the potential benefits as envisioned from the point of view of pure science. From a bioethical and societal perspective, the book represents a remarkable relapse into a science-only, pre-HGP approach to science. It is as if the many fruitful collaborations between genomics researchers and experts from social sciences and the humanities, in order to analyse and assess the societal implications of genomics, did not yield any noticeable results. This is disappointing, especially because, in previous books and papers published by this highly influential author, a much more interdisciplinary approach was taken, and social, ethical and philosophical issues were taken on board. Indeed, as a director of the HGP, Collins was responsible for the ELSI programme as well. While the complexities of living systems are finally recognised, the complexities involved in the societal embedding of genomics (in health care and other areas) are suddenly underestimated in a rather disquieting way. I do not consider this a very promising course to take. 
${ }^{1}$ Centre for Society and the Life Sciences, Nijmegen. h.zwart@science.ru.nl

${ }^{2}$ This article is part of the research programme of the Centre for Society and the Life Sciences (CSG), funded by the Netherlands Genomics Initiative (NGI). A draft version of this review was presented during a recent guest seminar at Egenis (University of Exeter, UK). The comments received from the Egenis team and other audience members on that occasion were much appreciated.

${ }^{3}$ F. Collins. 2006. The Language of God. A scientist presents evidence for belief. New York: Free Press (Simon \& Schuster).

${ }^{4}$ Here, the human genome had the first big disappointment in store for us. As Collins phrases it in this book: "One major surprise from the Human Genome Project was the discovery that human DNA contained only 20,000 protein-coding genes. We expected a lot more than that! Even the lowly roundworm has about 19,000 genes. Some observers were actually upset by this apparent downgrading of our importance, but we assume our genome must be fancier in some other way. After all, we are the only species that has sequenced our own genome!" (p.8) Collins goes on to argue that while the human genome contains vast areas of gene deserts - "as our genome is littered with repetitive sequences that have been inserted during a series of ancient assaults by various families of DNA parasites" (p.9) alternative splicing provides the beginning of an answer to the question of how the complexities of human existence can be brought about by a relatively low number of genes

${ }^{5}$ M. Serres. 1968. Hermes 1: La communication. Paris: Les Éditions de Minuit.

${ }^{6}$ M. Serres. 1972. Hermes 2: L'interférence. Paris: Les Éditions de Minuit ; M. Serres. 1977. Hermes 4: La distribution. Paris: Les Éditions de Minuit.

${ }^{7}$ For this genre, this is one of my favourite quotes: "[My life] happened to coincide with the most dramatic burst of knowledge in the whole history of mankind... Life itself has yielded its secrets, its central mechanisms have been unravelled in intimate detail and its history has been probed back to [its] origin." C.de Duve. 2002. Life Evolving. Molecules, mind and meaning. Oxford / New York. Oxford University Press, p.vii. See also: "Today, it is no exaggeration to state that we know the secret of life. In just half a century, mankind has made the biggest leap in knowledge in its whole history." Ibid, p.9; Cf. "DNA is the universal language of all living things. We are in a truly historic era, when this language ... is being revealed for the first time" Collins 2010, p.6.

${ }^{8}$ F. Collins. Has the revolution arrived? Nature 1 April 2010; 464: 674-675.

${ }^{9}$ C. Venter. Multiple Personal Genomes Await. Nature 1 April 2010; 464: 676-677.

${ }^{10}$ E. Hayden. Human Genome at Ten: Life is Complicated. Nature 1 April 2010; 464: 664-667.

${ }^{11}$ S. Freud. 1900/1942. Die Traumdeutung. Gesammelte Werke II/III. London: Imago.

${ }^{12} \mathrm{Cf}$. H. Zwart. On decoding and rewriting genomes: A psychoanalytical reading of a scientific revolution. Medicine, Healthcare and Philosophy 2011; 15 (1).

http://www.springerlink.com/content/1386-7423/preprint/

${ }^{13}$ L. Althusser and E. Balibar E. 1970. Lire le capital. Paris: Maspero.

${ }^{14}$ The stars of the HGP find themselves in quite the same position as the stars from the global cinematic, musical or athletic scenes: they are highly dependent on mass media for their success and at the same time pretend to abhor its workings. 